\title{
Inderjit (ed.): Management of Invasive Weeds
}

\author{
Springer, New York NY, 2009, 363 pp, US\$149, ISBN 978-1-4020-9202-2
}

\author{
Ingrid M. Parker · Pete Holloran · Sarah M. Swope • \\ Justin Cummings $\cdot$ Sara Grove $\cdot$ Carla Fresquez
}

Received: 9 July 2009/Accepted: 21 July 2009/Published online: 6 August 2009

(C) The Author(s) 2009. This article is published with open access at Springerlink.com

The management of invasive weeds is a complex and often expensive enterprise that requires ecological science, evolving technology, and collaboration across disciplines and sectors of society. Those involved in the day-to-day control of invasive species need access to cutting-edge and locally relevant information about the species they combat. The best resources for this information are more likely to be found on the internet or local information networks rather than in an edited volume of international scope, and most resource management agencies have few funds to purchase books (especially one that costs US\$149).

If a book on management of invasive weeds is not for managers, then, who is it for? Such a book could be useful for applied researchers, for those involved in resource management policy, for academics who want to forge links between basic biology and management, and for graduate students training to be managers or applied scientists. We used this recent volume, Management of Invasive Weeds, edited by Inderjit, in a graduate seminar that brought together both natural and social scientists, including students with varying degrees of both experience and aspirations in the management of invasive plants. The range of topics covered in the book, as well as the dual

I. M. Parker $(\bowtie) \cdot$ P. Holloran · S. M. Swope ·

J. Cummings $\cdot$ S. Grove $\cdot$ C. Fresquez

University of California, Santa Cruz, CA, USA

e-mail: parker@biology.ucsc.edu questions of what managers need and who might benefit from this type of book, provided rich fodder for discussion and led to a lively interchange among diverse points of view.

Given the ready access to journal articles that most academic scientists now enjoy, what is the role of edited volumes, especially expensive ones? Having reviewed other volumes on invasive species (e.g., Species Invasions, edited by Sax et al.), our reading group believes that edited volumes should be held to a higher standard than a mere collection of journal articles; a book should be more than the sum of its parts. This points to the greatest weakness of the present volume. It lacks many of the basic structural elements that provide a book with coherence and cohesiveness: an organizing principle, substantial introductory and synthesis chapters, even a complete list of authors and their affiliations. The authors do not cite each other's chapters, giving the impression that there was no attempt to bring researchers together to provide new, synergistic insights. The editor does supply a one-page preface that lists four aims, but these aims do not appear to guide the book in its final form. In fact, there is no clear organizational structure: no subsections and no consistent logic to the order of the chapters. The apparent lack of coordination among authors led to redundancy in places.

So this book's sum cannot be said to be more than its parts. What of the parts? Of the seventeen chapters, there are nine chapters that review particular topics, such as economic impacts (Chap. 1), early 
detection and monitoring $(2,6)$, the role of ornamental horticulture (9), eradication (3), impacts and management on a landscape/regional scale $(5,7)$, weeds in agricultural systems (8), and biological control with microbes (10). The other eight chapters are case studies, either of particular invasive plant species $(11,12,13,14,15)$, or of the management of particular sites or particular regions $(4,8,16)$.

There are some excellent chapters in this volume, papers we would recommend highly to anyone seeking an overview of a specific topic. Mack and Foster produced a nicely written and well-organized review of large-scale eradication projects, providing the most up-to-date and useful summary of this topic published anywhere. D'Antonio et al. thoughtfully consider the management of widespread grass invasions in the context of resistance and resilience paradigms. They urge a shift in perspective toward post-restoration management for resilient native assemblages and toward specific goals that deal pragmatically with persistent invaders. Brooks and Klinger consider invasive species monitoring programs from a practical perspective; they review how different types of data can be utilized and discuss the possibilities and challenges of using predictive models as an early detection tool. Walters' case study of Caulerpa taxifolia is an excellent summary not just of the original Mediterranean experience, which has been treated elsewhere, but also of recent eradication projects in both the United States and Australia. This story contains a particularly interesting lesson on post-eradication monitoring.

Some of the most innovative chapters are those that bring together two authors with markedly different perspectives. For example, Niemiera, a horticulture researcher, and Von Holle, an ecologist, describe the role the ornamental horticulture industry plays in both the problem and regulation of plant invasions. In some chapters, collaborations between more academic and more applied researchers provide a nice balance between theoretical ideas and realism. That said, we would have liked to see even more chapters that incorporated the voices of people on the ground. Many of the pressures experienced by managers-intense budget constraints, political controversies, opposition to herbicide use, etc.,-—are barely addressed.

An opportunity that is missed all too often in the literature on weed management is the incorporation of relevant social science and policy. Many of the chapters in this book would have benefited from incorporating such research. The theory of behavior change implicit in most chapters (and explicit in others) is that better information will lead to better outcomes. If managers have better information (in the form of georeferenced spatial data, for example, or weed risk assessments), they will make better decisions. If the public has better information about the impact of invasive plant species, they will curb activities that lead to their spread. However, there is ample theoretical and empirical evidence demonstrating the limitations of this model of behavior change. Information alone does not change behavior. We could all benefit from learning more about how social, political, and psychological factors shape and constrain the incorporation of scientific approaches into invasive species management.

An edited volume that represents a more active collaboration between natural scientists, social scientists, and managers could provide exciting and novel insights into the management of invasive plants. Such a volume would appeal to a broad range of academics and practitioners, and we hope someone will undertake it. In the meantime, despite its weaknesses, Management of Invasive Weeds has enough strong chapters that we would recommend that any research library purchase it. Those with limited budgets should contact individual authors.

Open Access This article is distributed under the terms of the Creative Commons Attribution Noncommercial License which permits any noncommercial use, distribution, and reproduction in any medium, provided the original author(s) and source are credited. 